\title{
El COVID-19 en el Perú
}

\section{COVID-19 in Peru}

\section{Ciro Maguiña-Vargas '}

La presente pandemia del Covid-19 sigue su rumbo imparable en todo el mundo a mediados del mes de setiembre del 2020. Estados Unidos de Norteamérica lidera los casos a nivel mundial, seguido de Brasil, India y, lamentablemente, el Perú está muy cerca de ellos. ${ }^{1}$

La contención de la enfermedad en los diversos países se ha dado de maneras variadas, que van desde las cuarentenas totales o parciales, el uso masivo de pruebas moleculares, toque de queda, entre otros. Pero el éxito de esas medidas está ligado a la oportunidad de su puesta en marcha, a la participación y colaboración de la población, al monitoreo constante de los vulnerables, etc.

En el Perú, la pandemia comenzó con el primer caso procedente de Europa, el 6 de marzo del 2020, y el 15 de ese mes el presidente Vizcarra anunció, antes que muchos países en América, una cuarentena total con toque de queda en todo el territorio nacional, que inicialmente tuvo una gran aceptación y acatamiento. ${ }^{2,3}$ Pero, con el transcurrir del tiempo la medida se debilitó y a partir de la quinta semana ya no funcionó, motivando que la curva de infectados continuara en alza sostenida. Las diversas estrategias de contención a las que se las denomino "martillo" no funcionaron y la curva ascendente nunca decayó, salvo Loreto y Lambayeque dónde la curva cayó de manera rápida a las diez semanas del brote con el colapso total del sistema de salud. ${ }^{4}$

La implementación de los bonos de alimentos tampoco tuvo el éxito esperado porque en cierta medida motivó el aumento de los contactos (colas y aglomeraciones para cobrarlos). Otras medidas, como las restricciones de salida para hombres y mujeres en días alternos, la cuarentena focalizada y los equipos de respuesta rápida no surtieron el efecto esperado. A todo esto, se suma que alrededor del $70 \%$ de nuestra población labora en la informalidad, con lo cual gran parte de esta salió a las calles para ganarse el pan de cada día. ${ }^{5}$

I Profesor principal. Facultad de Medicina, Universidad Peruana Cayetano Heredia. Vicedecano del Colegio Médico del Perú. Lima, Perú.
Maguiña-Vargas, C. El COVID-19 en el Perú. Rev Soc Peru Med Interna. 2020;33(4): I29-I3I.

https://doi.org/10.36393/spmi.v33i4.558

La suma de estos factores trajo como consecuencia el colapso del sistema sanitario, ya de por sí débil e ineficiente. La clarinada de alerta se dio en Loreto, con la falta de oxígeno y, sucesivamente, fueron afectados Lambayeque, Piura, Pucallpa, Ica, Arequipa y todo el sur del país, además de Ayacucho, Huancavelica, Cusco y Puno, acabando con el mito que las grandes alturas protegen de este flagelo.

En el Perú, en la semana 13 el presidente señaló que se había llegado a la ansiada meseta de contagios por COVID-19 pero, luego de un breve descenso de contagios de tres semanas continuas, el número de contagios y muertes volvió a subir. Al 18 de setiembre, el Ministerio de Salud informa que se han registrado 3667968 personas muestreadas y se han detectado un total de 762865 casos confirmados de COVID-19, 2905103 con resultados negativos y un total de 31369 fallecidos. $^{6}$

\section{¿Por qué esta dura realidad en nuestro país?}

\section{Elementos estructurales}

El Perú, según muchos economistas, tenía una economía sólida que crecía y era un ejemplo en América Latina. Hoy, hemos visto que no era así; ese crecimiento estaba basado en las actividades clásicas primarias de exportación, de minería y agroindustria, parte de un modelo económico de tipo neoliberal que viene aplicándose en nuestro país. Lo cierto es que la economía informal, de la que depende el 70\% de la población, sufrió un duro golpe con la cuarentena y es tal vez la causa más importante del fracaso en la contención de la pandemia. El lema "Quédate en casa", que al principio parecía correcto, no era sostenible en la práctica y por eso la presencia de miles de ambulantes en las calles en plena cuarentena. De ahí surge la denominación de "cuarentena chicha".

Parece que el auge de esa economía informal ahora nos pasa factura. A ello se suma que, a causa de la gran pobreza existente en el país, el hacinamiento afecta a miles de hogares, lo que contribuye al mayor y más rápido contagio, como se ha visto reflejado claramente en los amplios sectores urbano marginales pobres de Loreto, Lambayeque, Callao 
y de la gran Lima, en cuyos conos y distritos populosos, las familias numerosas viven en espacios pequeños, a veces en un solo cuarto. Hace unas semanas murieron jóvenes en una discoteca debido a una cultura "chicha", que se refleja en la incapacidad de muchos peruanos para respetar y hacer respetar las reglas. Así, muchos de los asistentes estaban infectados con el COVID-19 y lo siguen propagando por donde van.

\section{Responsabilidad del Gobierno}

A pesar de los aportes económicos del gobierno para la lucha contra la pandemia, y la adopción de medidas como la implementación de la Villa Panamericana para aislar a los contagiados por el virus, entre otras disposiciones, eso no ha bastado y ha dejado notar que desde el inicio de la pandemia faltó una planificación global e integral para su contención; muestra de ello fue el ínfimo presupuesto inicial de 3 millones 700 mil soles, que posteriormente fue corregido. $^{7}$ También faltó un sólido comando nacional que lidere ese combate, sumado a la pasividad y mala gestión de muchas autoridades responsables del Ministerio de Salud, lo que motivó el cambio de dos ministros de salud, además de las marchas y contramarchas en muchas medidas, como la recomendación del uso de guantes, los días de salida diferentes para hombres y mujeres, etc.

El enfoque hospitalario adoptado para enfrentar la pandemia, si bien es vital e importante para salvar vidas, se ha constituido en la visión central de este gobierno desde el inicio hasta ahora, pero ha motivado el descuido total del enfoque de contención de atención primaria comunitaria, que demanda la coordinación del nivel central con los alcaldes, agentes comunitarios y la población.

Dicho enfoque, en la práctica, nunca se dio de manera real, integral y coordinada, salvo contadas excepciones en Lima y algunas regiones. También hay que lamentar la pasividad de acciones, como la falta de dotación oportuna de los equipos de protección personal (EPP) para el personal de salud y la baja calidad de los equipos distribuidos, que ha causado hasta hoy la infección de miles de trabajadores de salud con el COVID-19, entre ellos 180 médicos fallecidos. Otra falencia ha sido la incapacidad para prever y dotar de oxígeno a tiempo a los pacientes, siendo un elemento primordial para el tratamiento, y que ha causado miles de muertos en casi todo el país. El saldo es, lamentablemente, el colapso del sistema sanitario en la casi totalidad de las regiones del país, incluyendo a Lima y el Callao.

Un tema aparte es el empleo de las pruebas de diagnóstico. $\mathrm{Si}$ bien las moleculares son las ideales para el rastreo de los pacientes asintomáticos infectados, ellas eran escasas en el mundo al inicio de la pandemia; por ello, el gobierno compró las pruebas rápidas debido a la facilidad y rapidez en el diagnóstico, permitiendo un testeo amplio, aunque ha devenido en que la población se confíe de esta prueba, que tiene muchos falsos negativos y positivos. Es hora de cambiar ese método, aunque tarde, todavía debe hacerse. No se puede dejar de señalar que, en este contexto, salió a luz la incapacidad de muchas autoridades regionales, que fueron y son una traba para el manejo integral de la pandemia. Otra debilidad de la estrategia del gobierno fue y es la inexistencia de mensajes adecuados de comunicación para ganar el apoyo de la población, y no solo decir de manera pasiva "Quédate en casa", sabiendo que mucha gente es pobre y no tiene casa, y vive hacinada en cuartos insalubres.

\section{Crisis sanitaria}

La crisis sanitaria que arrastramos por más de 40 años nos pasa la factura de manera contundente en esta pandemia. Por lo que, al inicio de la pandemia, se vio la consecuencia de tener asignado un presupuesto ínfimo para el sector salud, un sistema sanitario desintegrado, hospitales antiguos y carentes de equipos y de personal de salud especializado, se encontró que solo se tenían cien camas en las unidades de cuidados intensivos en todo el país, y un solo laboratorio del Instituto Nacional de Salud para la toma y análisis de muestras de COVID- 19.

\section{No participación de la sociedad civil}

Otro factor que llama la atención en esta problemática es la escasa y casi nula participación de la sociedad civil; salvo el Colegio Médico del Perú que asumió su rol histórico en defensa de la salud, la vida de los pacientes y de los colegas médicos, de la Defensoría del Pueblo, algunas congregaciones religiosas y sectores empresariales, la gran mayoría de las instituciones civiles poco o nada han realizado en el apoyo a la contención de la pandemia.

\section{¿Qué hacer?}

Estamos a mediados de setiembre y el primer brote en el Perú recién tiende a disminuir a nivel nacional, esto es debido principalmente a la disminución de casos y fallecidos en Arequipa, Cusco, Moquegua y Puno. Además, se tiene estudios de prevalencia de hace algunas semanas; así, en Lima es el 25\%, en Lambayeque 31\% y Loreto $71 \%$, cifras que revelan que un grupo importante de peruanos se han infectado. ${ }^{8}$ Mientras tanto, en muchos países de Europa y en Australia se están produciendo nuevos rebrotes y no sabemos el curso posterior de los mismos ya que esta enfermedad es muy cambiante y siempre nos da sorpresas.

Por ahora, las únicas armas que tenemos para evitar contraer la enfermedad son el uso adecuado de las mascarillas, el distanciamiento social y el lavado racional de las manos con agua y jabón o el uso del alcohol.

Actualmente, hay alrededor de 200 grupos trabajando en todo el mundo en busca de una vacuna, y la Organización Mundial de la Salud (OMS) le está siguiendo la pista a unos 140 ensayos, algunos en fase dos y otros en fase tres; pero, siendo realistas, no es difícil que estas vacunas estén listas a muy corto plazo. ${ }^{9}$ Si todo va bien y no hay sorpresas, podríamos tener alguna vacuna disponible para el 2021 o el 2022. 


\section{REFERENCIAS BIBLIOGRÁFICAS}

1. Johns Hopkins University \& Medicine. COVID-19 Dashboard by the Center for Systems Science and Engineering (CSSE) at Johns Hopkins University. Baltimore, Maryland, USA: Johns Hopkins University \& Medicine; 2020. (Citado el 31 de agosto del 2020). URL disponible en: https://coronavirus.jhu.edu/map.html

2. Ministerio de Salud. Coronavirus en el Perú: casos confirmados. Lima: Ministerio de Salud; 2020. (Citado el 18 de setiembre del 2020). URL disponible en: https://www.gob.pe/8662-coronavirusen-el-peru-casos-confirmados

3. Presidencia del Consejo de Ministros. Decreto Supremo $N^{\circ} 044-$ 2020-PCM. Decreto Supremo que declara Estado de Emergencia Nacional por las graves circunstancias que afectan la vida de la Nación a consecuencia del brote del COVID-19. Lima: Diario Oficial El Peruano; 15 de marzo del 2020.

4. Burhum R. El Martillazo y el Huayno: COVID-19 en el Perú Las métricas más importantes pre y post cuarentena. San Francisco: Medium Corporation; 2020. (Citado el 18 de setiembre del 2020). URL disponible en: https://medium.com/@rburhum/el-martillazoy-el-huayno-278716f49938

5. Defensoria del Pueblo. Estado de Emergencia Sanitaria: El problema de la informalidad laboral en una economía confinada. Lima: Defensoria del Pueblo; 2020. (Citado el 18 de setiembre del 2020). URL disponible en: https:/www.defensoria.gob.pe/wp-content/ uploads/2020/04/Serie-de-Informes-Especiales-N\%C2\%B0-022020-DP-Problema-de-la-informalidad-laboral-en-una-economiaconfinada.pdf
6. Ministerio de Salud. Sala Situacional COVID-19. Lima: Ministerio de Salud; 18 de setiembre del 2020. (Citado el 21 de setiembre del 2020). URL disponible en: https://twitter.com/Minsa_Peru/ status/1307432567734403072/photo/1

7. Carmen-Moran J. Presidente causó pánico y alarma. Lima: Diario Expreso; 7 de marzo de 2020. (Citado el 18 de septiembre del 2020). URL disponible en: https://www.expreso.com.pe/destacadoportada/presidente-causo-panico-y-alarma/

8. Andina Agencia Peruana de Noticias. Perú tendrá preferencia para acceder a vacunas por ser parte de estudios clínicos. Lima: Andina Agencia Peruana de Noticias; 5 de setiembre del 2020. (Citado el 18 de septiembre del 2020). URL disponible en: https:/www.andina. pe/agencia/noticia-peru-tendra-preferencia-para-acceder-avacunas-ser-parte-estudios-clinicos-812583.aspx

9. BBC News Mundo. Vacuna contra la covid-19: cuáles están más avanzadas en la carrera por combatir el coronavirus (y por qué aún queda un largo camino). Londres: BBC News Mundo; 21 de julio 2020. (Citado el 18 de septiembre del 2020). URL disponible en: https://www.bbc.com/mundo/noticias-53487188

Lima, 21 de septiembre del 2020.

CORRESPONDENCIA:

Ciro Maguiña Vargas, ciro.maguina@upch.pe 